\title{
$\beta$-Hydroxybutyrate inhibits apoptosis in bovine neutrophils through activating ERK1/2 and AKT signaling pathways
}

\author{
Yuxiang Song, ${ }^{1}$ Kexin Wang, ${ }^{1}$ Juan J. Loor, ${ }^{2}$ Qianming Jiang, ${ }^{2}$ Yuchen Yang, ${ }^{1}$ Shang Jiang, ${ }^{1}$ Siyuan Liu, ${ }^{1}$ \\ Jiyuan He, ${ }^{1}$ Xiancheng Feng, ${ }^{1}$ Xiliang Du, ${ }^{1}$ Lin Lei, ${ }^{1}$ Wenwen Gao, ${ }^{1}$ Guowen Liu, ${ }^{1}$ and Xinwei Li ${ }^{1 *}$ \\ ${ }^{1}$ State Key Laboratory for Zoonotic Diseases, Ministry of Education, College of Veterinary Medicine, Jilin University, Changchun, Jilin Province, \\ 130062, China \\ ${ }^{2}$ Mammalian NutriPhysioGenomics, Department of Animal Sciences and Division of Nutritional Sciences, University of Illinois, Urbana 61801
}

\section{ABSTRACT}

Ketosis in dairy cows, a common metabolic disorder during the peripartal period, is accompanied by systemic inflammation and high concentrations of blood $\beta$-hydroxybutyrate (BHB). Neutrophil apoptosis plays a key role in maintaining the balance of inflammation and functional capacity of circulating neutrophils in ketotic cows. The kinases ERK1/2 and AKT, as well as their downstream Bcl-2 family-mediated mitochondrial signaling, are important apoptosis-regulating pathways in neutrophils. The objective of our study was to investigate the effects of BHB on neutrophil apoptosis and the underlying regulatory mechanisms during ketosis. Neutrophils were isolated from 5 multiparous cows (within 3 wk postpartum) with serum BHB concentrations $<0.6 \mathrm{~m} M$ and glucose concentrations $>3.5 \mathrm{~m} M$. In a series of experiments, neutrophils were treated with increasing concentrations of BHB $(0$, $0.6,2$, and $3 \mathrm{mM}$ for $10 \mathrm{~h})$ and time $(0,2,4,6,8$, and $10 \mathrm{~h}$ with $2 \mathrm{~m} M$ ). Subsequently, a $2 \mathrm{~m} M$ BHB dose was used to challenge neutrophils for $8 \mathrm{~h}$. Apoptosis rate of neutrophils and protein abundance of cleaved caspase 3 were lower after BHB treatment. Treatment with BHB decreased protein and mRNA abundance of the pro-apoptotic genes $\operatorname{Bax}(B A X)$ and $\operatorname{Bad}(B A D)$, whereas it increased mitochondrial membrane potential (MMP) and protein and mRNA of the anti-apoptotic genes Bcl-xL (BCL2L1) and Mcl-1 (MCL1). This indicated that a mitochondrial pathway was involved in the inhibition of neutrophil apoptosis via BHB. In addition, both SCH772984 (an inhibitor of the ERK1/2 signaling pathway) and MK-2206 (an inhibitor of the AKT signaling pathway) alleviated the BHB-induced anti-apoptotic function of the Bcl-2 family and the inhibition of MMP. Overall, our data demonstrated that

Received September 8, 2021.

Accepted December 17, 2021.

*Corresponding author: lixinwei100@126.com high concentrations of BHB inhibit apoptosis in bovine neutrophils by activating the ERK1/2 and AKT signaling pathways. These findings provide a theoretical basis for the understanding of systemic inflammation in ketotic cows.

Key words: dairy cow, $\beta$-hydroxybutyrate, neutrophils, apoptosis

\section{INTRODUCTION}

Ketosis is a metabolic disease characterized by increased blood concentration of ketone bodies, which typically occurs in dairy cows soon after calving. Ketotic cows are characterized by high concentrations of nonesterified fatty acids and BHB in the blood, along with systemic inflammation (Itle et al., 2015; Shen et al., 2021). The latter was associated with higher odds of developing other diseases, such as displaced abomasum, metritis, mastitis, lameness, and gastrointestinal disorders (Suthar et al., 2013; Berge and Vertenten, 2014; Pryce et al., 2016). Systemic inflammation not only impairs performance and reproduction but also shortens the lifespan of dairy cows, thereby causing loss of potential earnings in the dairy industry (Duffield et al., 2009). The underlying mechanisms linking nonesterified fatty acids, $\mathrm{BHB}$, and systemic inflammation in ketotic dairy cows are not well known.

Neutrophils contribute to the early innate immune response by rapidly migrating into inflamed tissues, and killing and clearing pathogens, along with amplifying inflammation (Daha, 2011). These cells are characterized by a short lifespan, with "old" or activated neutrophils eventually undergoing apoptosis as a safe elimination process mediated via programmed cellular death (Savill, 2000). In both humans (Haslett, 1999) and cows (Sládek and Rysanek, 2001), apoptosis in neutrophils provides the means to limit and resolve inflammation without releasing cytotoxic molecules. Apoptotic neutrophils are cleared by macrophages, a process that helps control inflammation by inhibiting 
secretion of IL- 6 and tumor necrosis factor $\alpha$ (TNF- $\alpha$ ), while promoting that of IL-10 and transforming growth factor- $\beta$ (TGF- $\beta$ ) from macrophages (Brostjan and Oehler, 2020). In cases where apoptosis is inhibited, cells continue to secrete proinflammatory mediators, including IL-6, myeloperoxidase, and reactive oxygen species, all of which intensify lipid oxidation and exacerbate systemic inflammation (Lawrence et al., 2020). Cows with severe negative energy balance (NEB) or ketosis have increased numbers of neutrophils and levels of proinflammatory cytokines in the circulation (Schulz et al., 2015; Abuajamieh et al., 2016). Clearly, data may suggest that blocking or curtailing neutrophil apoptosis is a potential cause of systemic inflammation in ketotic cows.

High levels of BHB induce lipotoxicity and are associated with the occurrence of inflammatory diseases, including mastitis and metritis (Lacetera et al., 2002; Hammon et al., 2006; Shi et al., 2015). Neutrophils in ketotic cows are exposed to high concentrations of BHB (BHB $\geq 1.2 \mathrm{mM}$; Duffield et al., 2009), and a connection with apoptosis in different types of cells, including neutrophils, has been reported (Achanta and Rae, 2017; Guo et al., 2019). Thus, high concentrations of BHB may potentially inhibit bovine neutrophil apoptosis, but the exact mechanisms are unknown.

Neutrophil apoptosis can be intrinsically (via mitochondria) regulated by members of the Bcl-2 family, which are categorized into anti-apoptotic, including Bcl2-like protein 1 (Bcl-xL) and myeloid cell leukemia 1 (Mcl-1), and pro-apoptotic subgroups, including apoptosis regulator $\mathrm{BAX}(\mathrm{Bax})$ and $\mathrm{Bcl} 2$-associated agonist of cell death (Bad; Adams and Cory, 1998; Antonsson and Martinou, 2000). Imbalance of apoptotic regulation within the Bcl-2 family decreases mitochondrial membrane potential (MMP), resulting in cytoplasmic release of cytochrome $\mathrm{C}$ and initiation of the apoptosis cascade (Pathak and Khandelwal, 2007; Ravichandran, 2010). Both ERK1/2 and AKT, 2 intracellular survival signaling pathways, are important regulators of the Bcl-2 family (Shrivastava et al., 2015). Over-activation of ERK1/2 and AKT leads to diminished apoptosis in different cell types, including neutrophils (Kilpatrick et al., 2006; Zhu et al., 2006). Importantly, it has been confirmed that short time of BHB treatment can significantly activate the AKT and ERK1/2 pathways in bovine neutrophils (Carretta et al., 2020). Additionally, in rats, BHB can upregulate the abundance of $\mathrm{Bcl}-2$ and downregulate abundance of Bax to alleviate hippocampus neuronal apoptosis induced by oxidative stress (Xie et al., 2015).

Given the important regulatory function of the ERK1/2 and AKT signaling pathways on neutrophil apoptosis and their close relationship with BHB, we speculated that activation of ERK1/2 and AKT in response to a high concentration of BHB mediates the inhibition of bovine neutrophil apoptosis. Thus, our general hypothesis was that BHB activates ERK1/2 and AKT signaling pathways, thereby leading to an anti-apoptotic outcome of Bcl-2 family, culminating in the inhibition of apoptosis in neutrophils. The overall objective of this study was to explore the effect of BHB on apoptosis in bovine neutrophils and the underlying mechanisms.

\section{MATERIALS AND METHODS}

\section{Animals}

The Ethics Committee on the Use and Care of Animals at Jilin University (Changchun, China) approved the present experimental protocol (no. 202012018). Animals used in the current study received humane care according to the principles and guidelines of the Guidelines for the Care and Use of Agricultural Animals in Research and Teaching, 3rd ed. (Fass Inc., 2010). The selection of experimental animals was similar to previous studies (Song et al., 2016; Du et al., 2018b). In brief, healthy dairy cows in the peripartal period with similar parities (median $=3$, range $=2-4$ ) and DIM (median $=6 \mathrm{~d}$, range $=3-10 \mathrm{~d}$ ) were preselected from a dairy farm located in Changchun City (Jilin Province, China). Accordingly, 15 healthy cows (within 3 wk postpartum) with negative nitroprusside test in milk were preselected. To analyze the concentration of serum BHB and glucose of each cow, the blood sample was collected in the morning $(0700-0800 \mathrm{~h})$ for 3 consecutive days. Five healthy cows in mild NEB state (serum BHB content $<0.6 \mathrm{mM}$ and glucose content $>3.5$ $\mathrm{m} M$ ) were finally selected as donors of the PMN used in the present study (Itle et al., 2015; Song et al., 2021). All selected cows were housed in a climate-controlled barn with individual tiestalls, to reduce environmental interference. Cows had ad libitum access to the same diet (Du et al., 2018a), which was offered twice daily (0900 and $1630 \mathrm{~h}$ ), and fresh water was supplied continuously.

\section{Neutrophil Isolation and Culture}

Blood samples were harvested at 0700 to $0800 \mathrm{~h}$ from the jugular vein. A total of $200 \mathrm{~mL}$ of blood per cow per day was collected and kept at room temperature in trisodium citrate-containing tubes (Chengwu Medical Products Factory) until transport to the laboratory (within 30 min after collection) for subsequent neutrophil 
isolation. Neutrophils were isolated from whole blood samples using a commercial bovine peripheral blood neutrophils isolation kit following the manufacturer's protocol (cat. no. P9400; Solarbio Science and Technology Co. Ltd.). Cells were kept at room temperature throughout the procedure, to eliminate the influence of temperature change on the activity of neutrophils. For each isolation, $16 \mathrm{~mL}$ of neutrophil separation medium 1 , and $8 \mathrm{~mL}$ of neutrophil separation medium 2 were added to a $50-\mathrm{mL}$ sterile centrifuge tube. Subsequently, $20 \mathrm{~mL}$ of blood was added, and the mixture was centrifuged at $800 \times g$ for $30 \mathrm{~min}$. After centrifugation, the middle layer containing neutrophils was carefully aspirated and transferred to a new centrifuge tube. An equal volume of washing solution was added and centrifuged at $500 \times g$ for $10 \mathrm{~min}$. The supernatant was discarded, and erythrocyte lysis buffer (cat. no. R1010; Solarbio Science and Technology Co. Ltd.) was added to remove red blood cells. The remaining cells were washed twice with RPMI-1640 basic medium (cat. no. SH30809.01; HyClone Laboratories) and centrifuged for 10 min at $500 \times g$ to harvest neutrophils. The purity of the obtained PMNs was $\sim 97.5 \%$ with $\sim 95 \%$ viability. Neutrophils were seeded into a 24-well tissue culture plate $\left(1 \mathrm{~mL}\right.$ per well) at $1 \times 10^{6}$ cells $/ \mathrm{mL}$ using RPMI1640 basic medium (cat. no. SH30809.01; HyClone) supplemented with $10 \%$ fetal bovine serum (cat. no. FB15015; HyClone) and cultured at $37^{\circ} \mathrm{C}$ in $5 \% \mathrm{CO}_{2}$, followed by BHB treatment as described subsequently.

\section{Cell Treatment}

The BHB (cat. no. 55397; Sigma-Aldrich) powder was dissolved in PBS and sterilized by filtration. The concentrations of BHB used in our study were selected according to the normal and pathological hematology standards for dairy cows with or without ketosis (Ingvartsen and Moyes, 2013). Accordingly, neutrophils were maintained in RPMI-1640 and treated with $0,0.6$ (normal level), 2 (subclinical level), and $3 \mathrm{mM}$ (clinical level) BHB for $10 \mathrm{~h}$. The $2 \mathrm{~m} M$ BHB treatment had an obvious effect on neutrophil apoptosis. Thus, $2 \mathrm{mM}$ was selected as the treatment concentration for subsequent experiments. Neutrophils were then treated with $2 \mathrm{mM}$ BHB for $0,2,4,6,8$, and $10 \mathrm{~h}$. Accordingly, $8 \mathrm{~h}$ of BHB treatment had an obvious effect on neutrophil apoptosis, and $8 \mathrm{~h}$ was selected as the incubation time for subsequent experiments. To verify the regulatory role of ERK1/2 and AKT signaling on the BHB-induced inhibition of neutrophil apoptosis, the ERK1/2 inhibitor SCH772984 (300 $\mu M$, cat. no. 942183-80-4; Selleck) and the AKT inhibitor MK-2206 (200 $\mu$ M, cat. no. 1032350-13-2; Selleck) were preincubated for $0.5 \mathrm{~h}$ before BHB treatment, respectively.

\section{Detection of Neutrophil Apoptosis}

Percentage of apoptotic neutrophils were quantified by annexin V-fluorescein isothiocyanate (FITC)/propidium iodide (cat. no. 556547; BD Biosciences) double staining assay. Cells were washed twice with cold PBS. Cells were then resuspended in $100 \mu \mathrm{L}$ of $1 \times$ binding buffer, followed by staining with $5 \mu \mathrm{L}$ of annexin V-FITC and $5 \mu \mathrm{L}$ of propidium iodide in the dark at room temperature for $15 \mathrm{~min}$. Subsequently, $400 \mu \mathrm{L}$ of $1 \times$ binding buffer was added to each tube. The stained cells were examined immediately using flow cytometry (Becton Dickinson) within $1 \mathrm{~h}$. Each treatment had 5 replicates, each replicate repeated 3 times.

\section{Measurement of MMP}

The MMP was measured using a JC-1 kit (cat. no. C2006; Beyotime) according to the manufacturer's instructions. In brief, $1 \times 10^{6}$ cells were resuspended in $500 \mu \mathrm{L}$ of RPMI-1640 basic medium, followed by adding $500 \mu \mathrm{L}$ of JC-1 (tetraethylbenzimidazolylcarbocyanine iodide) working stock. Cells were reversed and mixed several times and then incubated at $37^{\circ} \mathrm{C}$ for $20 \mathrm{~min}$. Cells were washed twice with $1 \times \mathrm{JC}-1$ binding buffer and centrifuged for $3 \mathrm{~min}$ at $600 \times g$. Samples were resuspended and examined immediately using flow cytometry (Becton Dickinson) within $1 \mathrm{~h}$. The gating strategy is based on the distribution of cells in the negative staining control, the positive control, and experimental groups (Raju et al., 2013; Chen et al., 2018). Each treatment had 5 replicates, each replicate repeated 3 times. At low concentrations (due to low MMP), JC-1 is predominantly a monomer in the cytosol, yielding green fluorescence detected through the FITC channel of flow cytometry. At high concentrations (due to high MMP), the dye aggregates, yielding a red-colored fluorescence inside the mitochondria, detected through the phycoerythrin (PE) channel.

\section{Protein Extraction and Western Blotting}

Total protein from neutrophils was extracted using a commercial protein extraction kit (cat. no. C510003; Sangon Biotech Co. Ltd.) according to the manufacturer's instructions. The protein concentration was measured via the bicinchoninic acid method (cat. no. P1511; Applygen Technologies). A total of $30 \mu \mathrm{g}$ of protein from each sample was separated by $12 \%$ SDSPAGE with a known prestained protein ladder (cat. no. 26616; Thermo Fisher Scientific). The target protein on the gel was electrophoretically transferred to a polyvinylidene difluoride (PVDF) membrane. The PVDF membranes were blocked in 3\% BSA in Tris-buffered 
saline with $0.1 \%$ Tween-20 detergent (TBS-T) for $4 \mathrm{~h}$ at room temperature, followed by incubation overnight at $4^{\circ} \mathrm{C}$ with primary antibodies against cleaved caspase 3 (1:1,000; cat. no. AF7022; Affinity Biosciences Inc.), caspase 3 (1:1,000; cat. no. AF6311; Affinity Biosciences Inc.), Bax (1:1,000; cat. no. ab32503; Abcam), Bad (1:1,000; cat. no. 9292; Cell Signaling Technology Inc.), Bcl-xL (1:1,000; cat. no. 2764; Cell Signaling Technology Inc.), Mcl-1 (1:1,000; cat. no. ab32087; Abcam), phosphor-AKT (1:1,000; cat. no. 4060; Cell Signaling Technology Inc.), AKT (1:1,000; cat. no. 9272; Cell Signaling Technology Inc.), phosphor-ERK1/2 (1:1,000; cat. no. 4370; Cell Signaling Technology Inc.), ERK1/2 (1:1,000; cat. no. 4695; Cell Signaling Technology Inc.), and $\beta$-actin $(1: 2,000$; cat. no. ab8226; Abcam), respectively. Subsequently, PVDF membranes were washed with TBS-T 3 times and incubated with horseradish peroxidase-conjugated anti-rabbit $(1: 5,000$; cat. no. SA00001-2; ProteinTech Group Inc.) or anti-mouse (1:5,000; cat. no. SA00001-1; ProteinTech Group Inc.) immunoglobulin at room temperature for $1 \mathrm{~h}$. After washing PVDF membranes another 3 times with TBS$\mathrm{T}$, immunoreactive bands were visualized by enhanced chemiluminescence solution (cat. no. WBKLS0500; Millipore). Each treatment had 3 replicates, each replicate repeated 3 times. $\beta$-Actin was used as a reference protein. Lastly, all bands were imaged using a Protein Simple Imager (ProteinSimple), and their gray value was analyzed using Image-Pro Plus 6.0 (Media Cybernetics). All antibodies can react with bovine target proteins.

\section{Quantitative Reverse-Transcription PCR Assay}

Quantitative reverse-transcription PCR was performed as described previously (Song et al., 2021).
Total RNA from neutrophils was extracted using Trizol (cat. no. 15596026; Invitrogen) according to the supplier's protocol. The RNA concentration and quality were measured using a K5500 MicroSpectrophotometer (Beijing Kaiao Technology Development Ltd.) and electrophoresis (1\% agarose gels). Then $1 \mu \mathrm{g}$ of total RNA from each sample was reverse-transcribed to cDNA using a PrimeScript Reverse Transcriptase Kit (cat. no. 6110B; TaKaRa Biotechnology Co. Ltd.). Primers of target genes, as shown in Table 1, were designed by Primer Express software 3.0 (Applied Biosystems Inc.). The mRNA abundance was detected using a SYBR green plus reagent kit (cat. no. 4913850001; Roche) with the 7500 Real-Time PCR System (Applied Biosystems Inc.). Conditions used for the PCR method were as follows: $95^{\circ} \mathrm{C}$ for $3 \mathrm{~min}$, followed by 40 cycles of $95^{\circ} \mathrm{C}$ for $15 \mathrm{~s}$ and $60^{\circ} \mathrm{C}$ for $1 \mathrm{~min}$. Relative transcription of target genes was normalized to the geometric mean of cycle threshold (CT) values of $A C T B$ and $Y W H A Z$ and determined by the $2^{-\triangle \Delta \mathrm{CT}}$ method (Zhang et al., 2005; De Ketelaere et al., 2006; Song et al., 2021). Each treatment had 3 replicates, each replicate repeated 3 times.

\section{Statistical Analysis}

Data of dose-dependent and time-dependent effects, whose residuals were found normally distributed after Shapiro-Wilk test, were expressed as least square means \pm standard error of the mean (SEM). Linear and quadratic contrasts were conducted to evaluate dose-dependent and time-dependent effects. Data of the other experiments were found normally distributed after Shapiro-Wilk test and expressed as means \pm SEM. A two-way ANOVA was used to assess the effects of 2 treatment factors (BHB and SCH772984; BHB and MK-2206) on apoptosis rate, pro- and anti-apoptotic

Table 1. Primer sequences used for quantitative real-time PCR

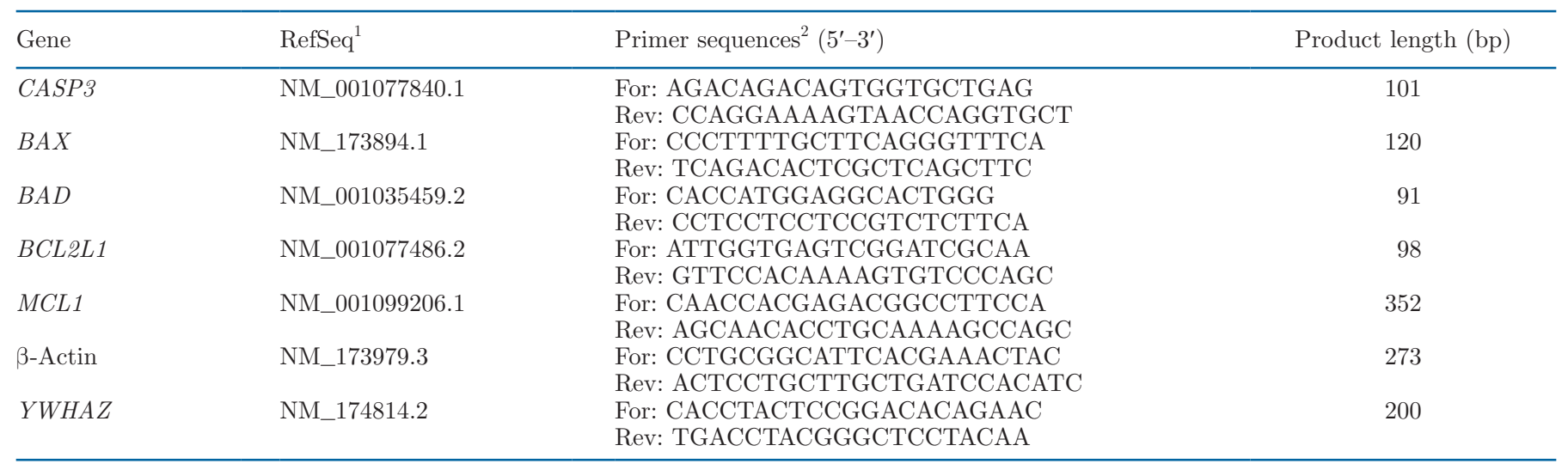

${ }^{1}$ Reference sequence accession number (https://www.ncbi.nlm.nih.gov/nuccore/).

${ }^{2}$ For $=$ forward; Rev $=$ reverse. 
mRNA and proteins, and MMP, including a Bonferroni post-hoc analysis when significant interaction occurred. One-way ANOVA with subsequent Bonferroni correction or independent-samples $t$-tests were used when there was only one treatment factor. We used SPSS 19.0 software (IBM Corp.) to determine the effects of concentration and time gradient BHB stimulation on PMN apoptosis, and GraphPad Prism 8.0 was used for the rest of the data. We considered $P<0.05$ to be significant and $P<0.01$ to be markedly significant.

\section{RESULTS}

\section{BHB Inhibits Bovine Neutrophil Apoptosis}

We found linear $(P<0.0001)$ and quadratic effects $(P<0.0001)$ for apoptosis rate due to the increase in dose of BHB (Figure $1 \mathrm{~A}, \mathrm{~B})$. Compared with control (0 $\mathrm{m} M \mathrm{BHB})$, no difference in apoptosis rate was detected with $0.6 \mathrm{~m} M$ BHB $(P=0.706$, Figure $1 \mathrm{~B})$. However, both $2 \mathrm{~m} M$ BHB $(P<0.0001$, Figure $1 \mathrm{~B})$ and $3 \mathrm{~m} M$ BHB $(P<0.0001$, Figure $1 \mathrm{~B})$ led to lower apoptosis rates. Regarding incubation time, we observed linear $(P<0.0001)$ and quadratic effects $(P<0.0001)$ for apoptosis rate with a peak response at $8 \mathrm{~h}$ (Figure 1 C, D). Thus, $2 \mathrm{~m} M$ BHB and $8 \mathrm{~h}$ were selected as ideal conditions for subsequent experiments $(P<0.0001$, Figure $1 \mathrm{~B}$ ). Protein abundance of cleaved caspase 3 (CASP3), the main marker of apoptosis, was lower in the BHB treatment group $(P<0.0001$, Figure $1 \mathrm{E}, \mathrm{F})$. However, mRNA abundance of CASP3 did not change with BHB treatment $(P=0.09$, Figure $1 \mathrm{G})$.

\section{BHB Promotes the Anti-Apoptotic Outcome of the Bcl-2 Family}

Compared with the control group, abundances of pro-apoptosis proteins Bax $(P<0.0001$, Figure $2 \mathrm{~A}$, $\mathrm{B})$ and $\operatorname{Bad}(P<0.0001$, Figure $2 \mathrm{~A}, \mathrm{C})$ was lower, whereas those of anti-apoptosis proteins Bcl-xL $(P<$ 0.0001, Figure 2 A, D) and Mcl-1 $(P<0.0001$, Figure 2 A, E) were greater after BHB treatment. In agreement with these responses, mRNA abundances of $B A X(P<$ 0.01 , Figure $2 \mathrm{~F})$ and $B A D(P<0.01$, Figure $2 \mathrm{G})$ were lower, but those of BCL2L1 $(P<0.0001$, Figure $2 \mathrm{H})$ and $M C L 1(P<0.0001$, Figure $2 \mathrm{I})$ were greater after BHB treatment.

\section{BHB Increases MMP in Bovine Neutrophils}

We observed a linear $(P<0.0001)$ and quadratic effect $(P<0.0001)$ for the ratio of FITC/PE mean fluorescence intensity with increased incubation time
(Figure 3 B). Compared with the control, as shown by the lower ratio of FITC/PE mean fluorescence intensity, MMP in neutrophils was greater after BHB treatment $(P<0.0001$, Figure 3 B $)$.

\section{BHB Inhibits Bovine Neutrophil Apoptosis Through Activation of the ERK1/2 and AKT Signaling Pathways}

Compared with the control, phosphorylation levels of ERK1/2 $(P<0.0001$, Figure $4 \mathrm{~A}, \mathrm{C})$ and AKT $(P<0.0001$, Figure $4 \mathrm{~B}, \mathrm{D})$ were greater in the BHB treatment group. We found that SCH772984 (300 nM; an inhibitor of ERK1/2) and MK-2206 (200 nM; an inhibitor of AKT) successfully inhibited phosphorylation of ERK1/2 $(P<0.0001$, Figure $4 \mathrm{~A}, \mathrm{C})$ and AKT $(P<0.0001$, Figure $4 \mathrm{~B}, \mathrm{D})$. Both SCH772984 $(P<$ $0.0001)$ and MK-2206 $(P<0.0001)$ relieved the inhibitory effect of BHB on neutrophil apoptosis (Figure $4 \mathrm{E}$, $\mathrm{F})$. As indicated by the greater ratio of FITC/PE mean fluorescence intensity, both SCH772984 $(P<0.0001)$ and MK-2206 $(P<0.0001)$ relieved the negative effect of BHB on neutrophil MMP (Figure $4 \mathrm{G}, \mathrm{H}$ ).

Consistent with Figure 2, compared with the control group, protein abundance of CASP3 was lower $(P<$ 0.01 , Figure 5 A, B) after BHB treatment, but no significant difference was found in its mRNA abundance $(P=0.99$, Figure $5 \mathrm{G})$. Compared with the control group, abundances of pro-apoptosis proteins $\operatorname{Bax}(P<$ 0.01 , Figure $5 \mathrm{~A}, \mathrm{C})$ and $\mathrm{Bad}(P<0.0001$, Figure $5 \mathrm{~A}$, D) were lower in the BHB treatment group, whereas abundances of anti-apoptosis proteins Bcl-xL $(P<$ 0.01 , Figure 5 A, E) and Mcl-1 $(P<0.001$, Figure 5 A, F) were greater. Compared with the control group, mRNA abundances of $B A X(P<0.01$, Figure $5 \mathrm{H})$ and $B A D(P<0.0001$, Figure $5 \mathrm{I})$ were lower after BHB treatment, but mRNA abundances of BCL2L1 $(P<$ 0.01 , Figure $5 \mathrm{~J})$ and $M C L 1(P<0.0001$, Figure $5 \mathrm{~K})$ were greater.

Protein abundance of CASP3 was greater $(P<$ 0.0001, Figure 5 A, B) after SCH772984 treatment. Abundances of pro-apoptosis proteins $\operatorname{Bax}(P<0.0001$, Figure $5 \mathrm{~A}, \mathrm{C})$ and $\mathrm{Bad}(P<0.0001$, Figure $5 \mathrm{~A}, \mathrm{D})$ were greater, but those of anti-apoptosis proteins Bcl$\mathrm{xL}(P<0.0001$, Figure $5 \mathrm{~A}, \mathrm{E})$ and Mcl-1 $(P<0.001$, Figure 5 A, F) were lower after SCH772984 treatment. Similarly, mRNA abundances of $B A X(P<0.0001$, Figure $5 \mathrm{H})$ and $B A D(P<0.0001$, Figure $5 \mathrm{I})$ were greater, whereas those of $B C L 2 L 1(P<0.0001$, Figure $5 \mathrm{~J})$ and $\operatorname{MCL} 1(P<0.0001$, Figure $5 \mathrm{~K})$ were lower after SCH772984 treatment. Similarly, MK-2206 played a similar role to that of SCH772984 on the abundance of the above Bcl-2 family proteins. Both MK-2206 and 


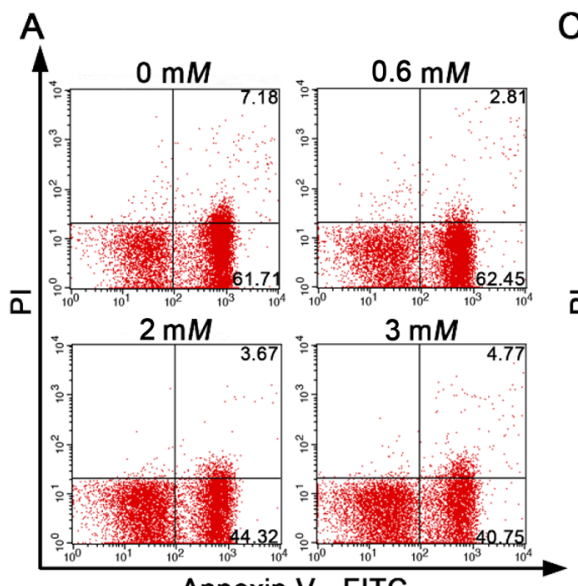

B

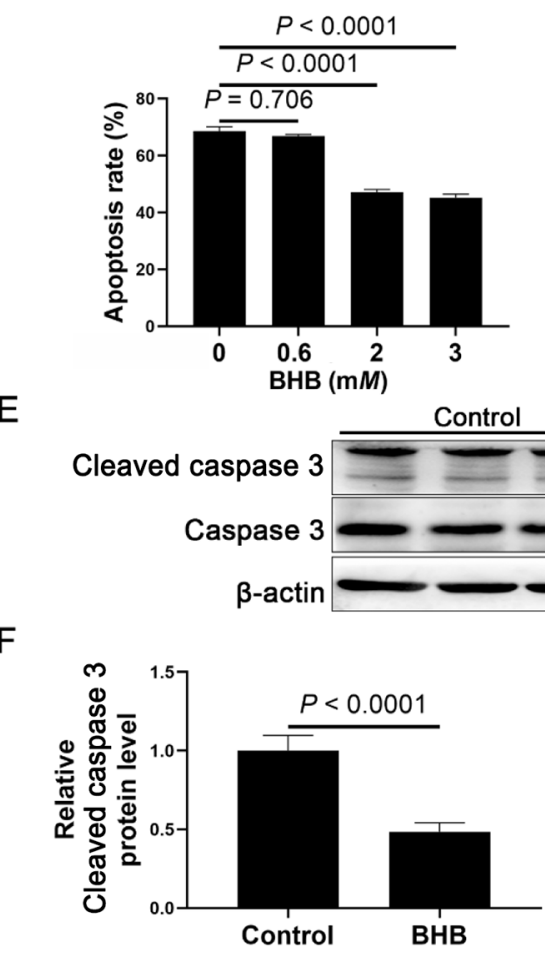

C
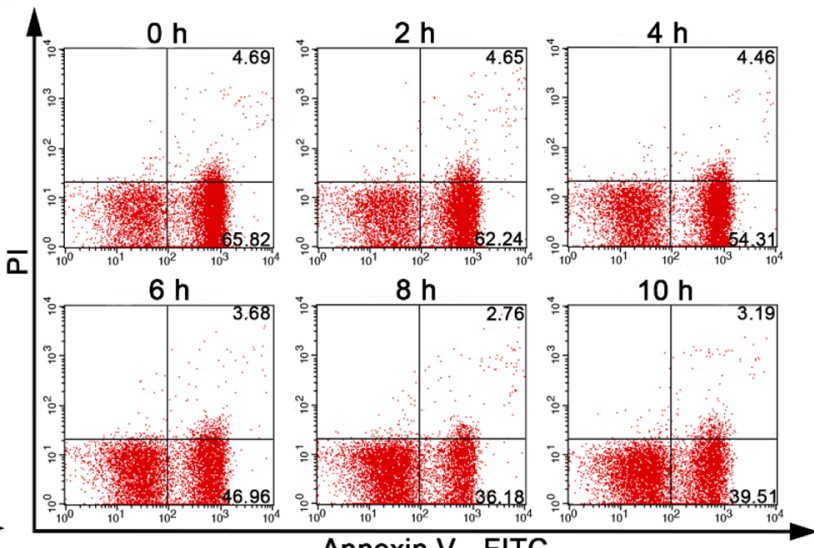

Annexin V - FITC

D

$P<0.0001$

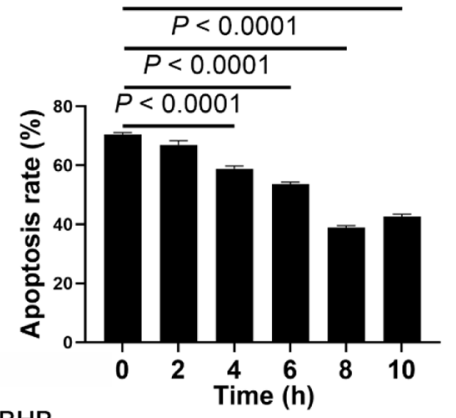

$\mathrm{BHB}$

$17 \mathrm{kDa}$

$13 \mathrm{kDa}$

$37 \mathrm{kDa}$

$42 \mathrm{kDa}$

G

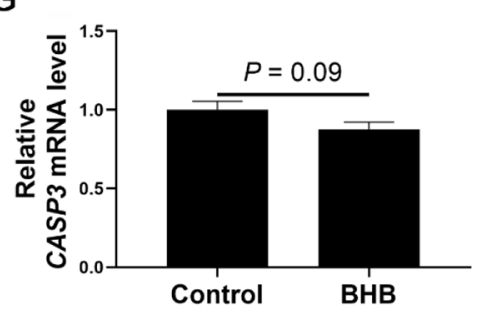

Figure 1. Effects of BHB on bovine neutrophil apoptosis. (A) Flow cytometry analysis of neutrophil apoptosis after BHB treatment Neutrophils were treated with $0,0.6,2$, and $3 \mathrm{mM}$ BHB for $10 \mathrm{~h}$, respectively. Annexin V-fluorescein isothiocyanate (FITC)/propidium iodide staining was used to identify apoptosis cells. Annexin $\mathrm{V}^{+}$cells were regarded as total apoptotic neutrophils. The numbers in the top-right and bottom-right quadrants indicate the percentages of late and early apoptotic cells, respectively. (B) Quantification of the total apoptotic rate of neutrophils in A. One-way ANOVA with subsequent Bonferroni correction was used to analyze the data. Linear increase $(P<0.0001)$ and quadratic effect $(P<0.0001)$ for the apoptosis rate were found, due to the increased dose of BHB. Data expressed as LSM \pm SEM. (C) Flow cytometry analysis of the effects of different duration times of BHB on neutrophil apoptosis. Neutrophils were treated with $2 \mathrm{~m} M$ BHB multiple times $(0,2,4,6,8$, and $10 \mathrm{~h})$. Stimulation with $2 \mathrm{~m} M$ BHB for $8 \mathrm{~h}$ was selected as ideal conditions for subsequent experiments. (D) Quantification of the total apoptotic rate of neutrophils in C. One-way ANOVA with subsequent Bonferroni correction was used to analyze the data. Linear increase $(P<0.0001)$ and quadratic effect $(P<0.0001)$ were found for the apoptosis rate with increased incubation time. Data expressed as LSM \pm SEM. (E) Protein abundance of cleaved caspase 3 and caspase 3. The 3 wells of each group represent 3 samples from different replicates, respectively. (F) Quantification of protein abundance in E. Data were analyzed with independent-samples $t$-tests. Data expressed as mean \pm SEM. (G) mRNA abundance of CASP3. Data were analyzed with independent-samples $t$-tests. Data expressed as mean \pm SEM. For western blotting experiments, $\beta$-actin was used to normalize protein abundance; for quantitative reverse-transcription PCR experiments, $A C T B$ and $Y W H A Z$ were used to normalize mRNA abundance. Statistical significance was declared at $P<0.05$, and $P<0.01$ was declared to be highly significant. 
SCH772984 inhibited the effect of BHB on the abundance of Bcl-2 family members (Figure 5).

\section{DISCUSSION}

Ketosis in peripartal dairy cows is often accompanied by systemic inflammation, which could lead to higher incidence of inflammatory diseases, including mastitis and metritis (Ingvartsen, 2006; Moyes et al., 2009; Ospina et al., 2010). Concentrations of BHB have been positively correlated with transcription and secretion of proinflammatory factors such as IL-6 and IL-8 in hepatocytes (Loor et al., 2007; Rodriguez-Jimenez et al., 2018). Thus, available data support the view (In- gvartsen, 2006) of a close relationship between BHB and systemic inflammation.

Inflammation is a crucial physiological response for the maintenance of tissue homeostasis, protecting the host against invading microorganisms, foreign substances, or molecules derived from damaged cells within the host (Medzhitov, 2010). Upon a challenge, important microcirculatory events occur within the host in response to the local release of proinflammatory mediators such as histamine, prostaglandins, leukotrienes, cytokines, and chemokines, leading to higher vascular permeability and increased leukocyte recruitment (Medzhitov, 2010). The regulation of neutrophil survival is critical to the propagation and resolution of

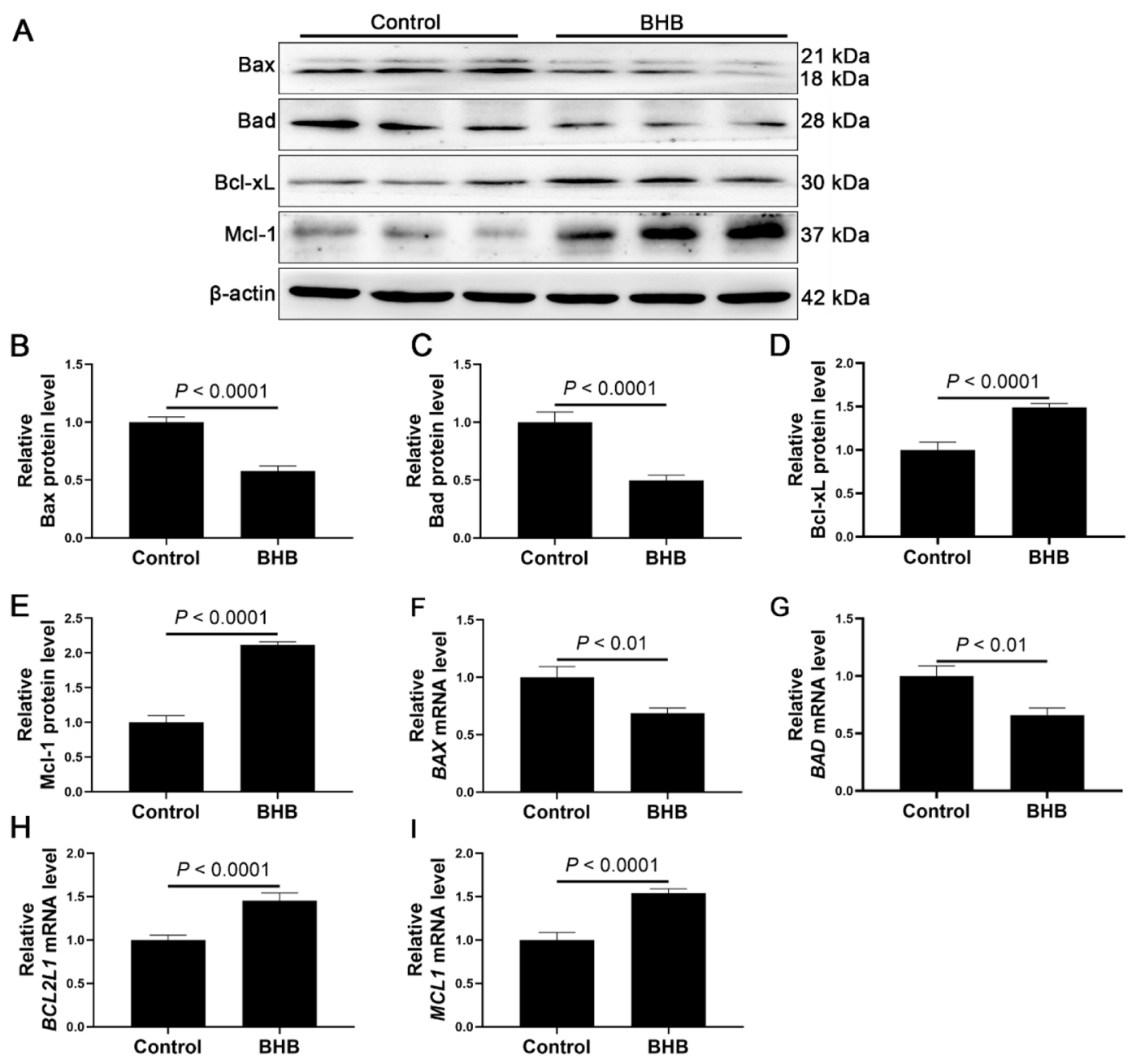

Figure 2. Effects of BHB on the expression of Bcl-2 family proteins. (A-E) Protein abundances of Bax, Bad, Bcl-xL, and Mcl-1. Representative blots in both groups are shown in A. The 3 wells of each group represent 3 samples from different replicates, respectively. Quantification is shown in B-E. (F-I) mRNA abundances of BAX, BAD, BCL2L1, and MCL1. For western blotting experiments, $\beta$-actin was used to normalize protein abundance; for quantitative reverse-transcription PCR experiments, $A C T B$ and $Y W H A Z$ were used to normalize mRNA abundance. Data were analyzed with independent-samples $t$-tests. Data expressed as mean \pm SEM. Statistical significance was declared at $P<0.05$, and $P<0.01$ was declared highly significant. 

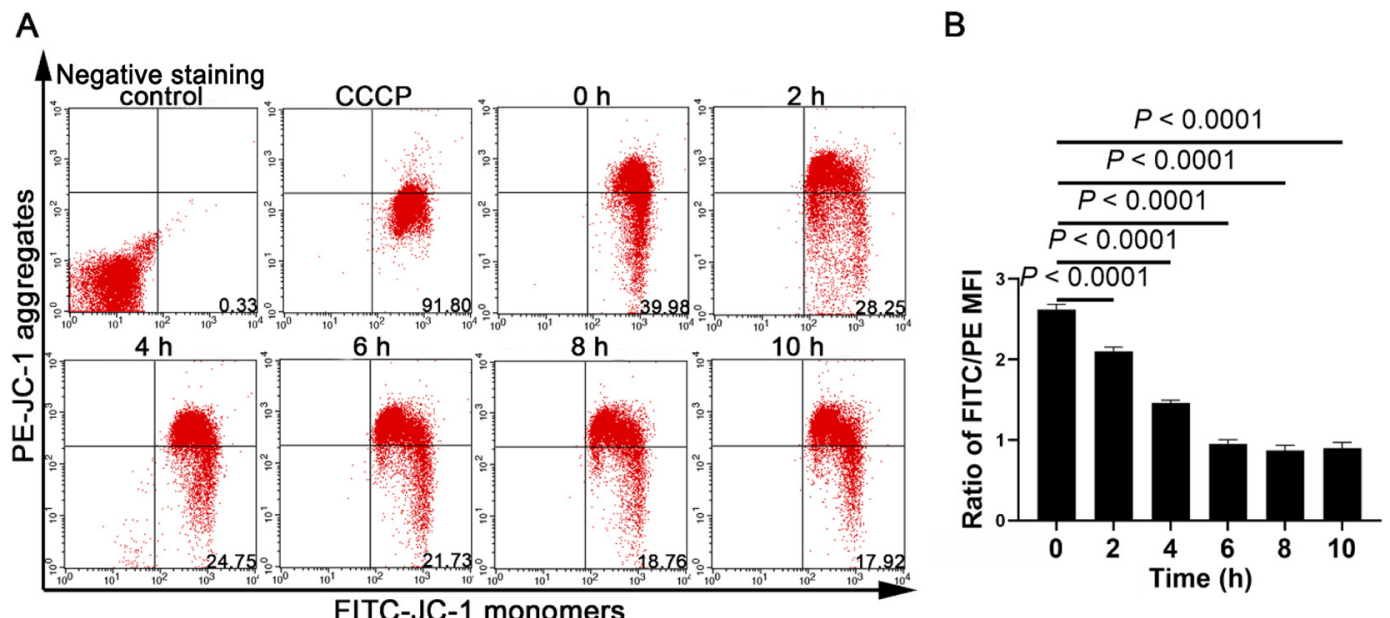

Figure 3. Effects of BHB on mitochondrial membrane potential (MMP) in bovine neutrophils. (A) MMP of bovine neutrophils. Tetraethylbenzimidazolylcarbocyanine iodide (JC-1) monomers yielding green fluorescence were detected through the fluorescein isothiocyanate (FITC) channel of flow cytometry; JC-1 aggregates yielding red-colored fluorescence were detected through the phycoerythrin (PE) channel. The gating strategy is based on the distribution of cells in the negative staining control, the positive control, and experimental groups. In positive control, neutrophils were treated with carbonyl cyanide 3-chlorophenylhydrazone (CCCP) to reduce the MMP. The numbers in the bottomright quadrants indicate the percentages of cells with low MMP. (B) Ratio of monomers to aggregates mean fluorescence intensity (MFI) in control and treatment. One-way ANOVA with subsequent Bonferroni correction was used to analyze the data. Linear increase $(P<0.0001)$ and quadratic effect $(P<0.0001)$ were found for the ratio of monomers with increased incubation time. Data expressed as LSM \pm SEM. Statistical significance was declared at $P<0.05$, and $P<0.01$ was declared to be highly significant.

inflammation (Davis et al., 2003). Neutrophils eventually end their lives through apoptosis, a noninflammatory way of death that limits its over-reaction (Korns et al., 2011; Dalli and Serhan, 2012; Tecchio and Cassatella, 2014). In chronic inflammatory diseases such as chronic bronchitis and rheumatoid arthritis, patients with systemic inflammation syndrome experience a dysregulated apoptosis of systemic neutrophils (Akgul et al., 2001), leading to increased circulating neutrophil numbers and elevated proinflammatory cytokine levels (Boutet et al., 2004).

Peripartal cows, especially those with severe NEB or ketosis, often have an increase in circulating neutrophil numbers and elevated serum IL-6 and TNF- $\alpha$ (Schulz et al., 2015; Abuajamieh et al., 2016). High concentrations of BHB can induce hepatocyte inflammatory injury in cattle through the NF- $\kappa \mathrm{B}$ signaling pathway (Shi et al., 2014). Furthermore, gene chip analysis has revealed that abundances of anti-apoptotic genes are upregulated and those of pro-apoptotic genes are downregulated in circulating neutrophils of metabolically stressed peripartal cows (Crookenden et al., 2019), suggesting a delay in neutrophil apoptosis. Thus, the inhibition of neutrophil apoptosis in response to BHB demonstrated in the present study confirmed that suggestion.

At least in nonruminants, proteins from the Bcl-2 family [key controllers of intrinsic (mitochondrial) apoptosis] regulate neutrophil apoptosis by balancing MMP (Lindsay et al., 2011; Ibrahim et al., 2020). Overexpression of Bcl-2 in mice has been found to lead to delayed neutrophil apoptosis, increased brain edema, hemorrhage, and poorer outcomes in a model of meningitis (Koedel et al., 2009). Thus, the fact that BHB downregulated the abundance of pro-apoptotic proteins, upregulated that of anti-apoptotic proteins, and slowed the decrease of MMP underscores the involvement of the Bcl-2 family in mediating the negative effects of BHB, impeding intrinsic apoptosis in bovine neutrophils.

Activation of the ERK1/2 and AKT signaling pathways promotes the abundance of anti-apoptotic proteins, including Mcl-1 and Bcl-xL, thereby prolonging their lifespan (Nakanishi et al., 2005). Along with the demonstration that even short-time BHB treatment (3 min) can promote phosphorylation of both ERK1/2 and AKT in bovine neutrophils (Carretta et al., 2020). In the present study, similar effects on ERK1/2 and AKT were found when BHB duration time increased to $8 \mathrm{~h}$. Our data demonstrated that inhibiting activation of both kinases can alleviate the negative effects of BHB on apoptosis.

In mice, annexin A1, an endogenous glucocorticoidregulated protein, can inhibit phosphorylation of ERK1/2 and increase protein abundance of Bax, thereby promoting neutrophil apoptosis, reducing ac- 
A

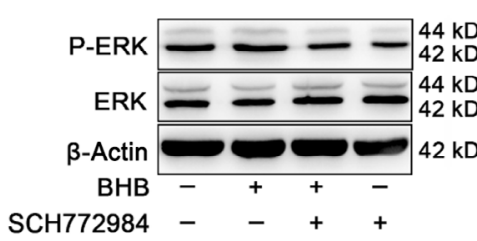

B

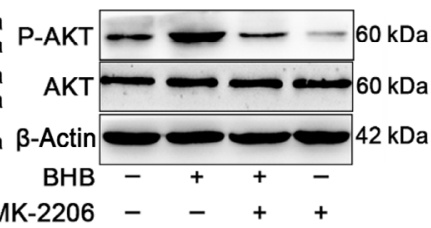

E

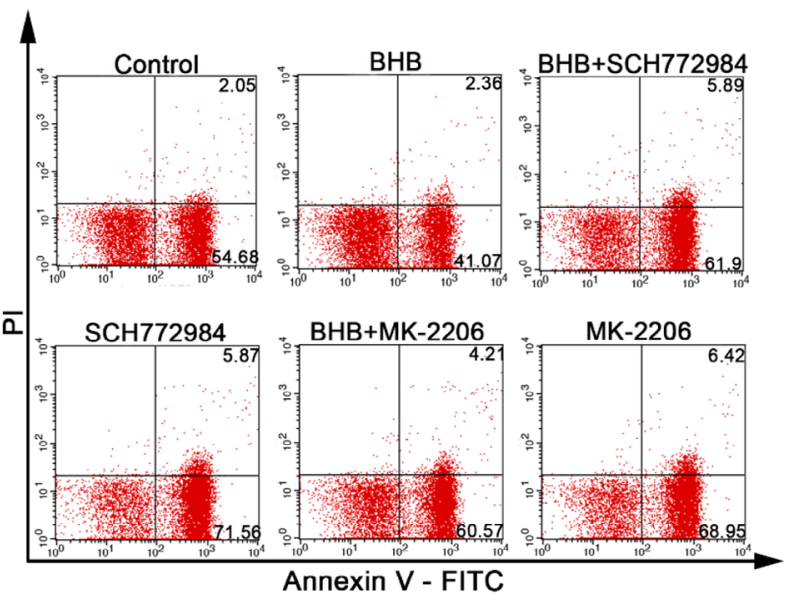

G

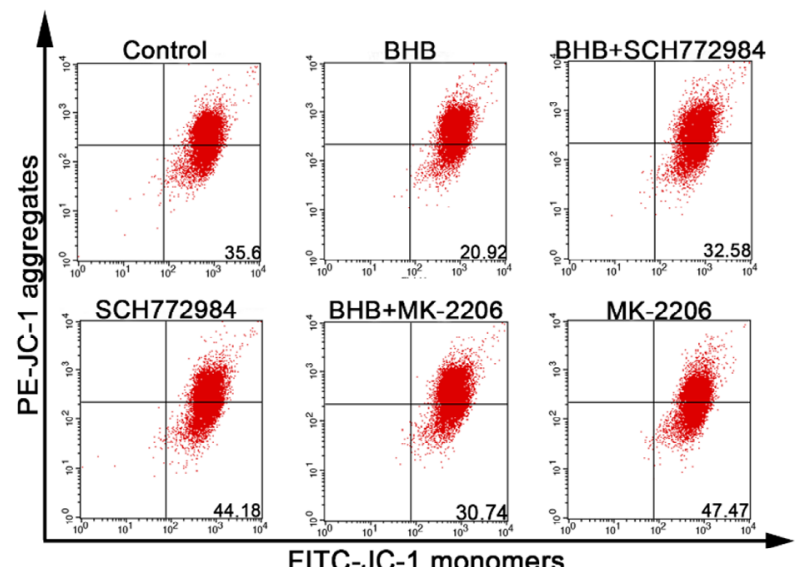

C

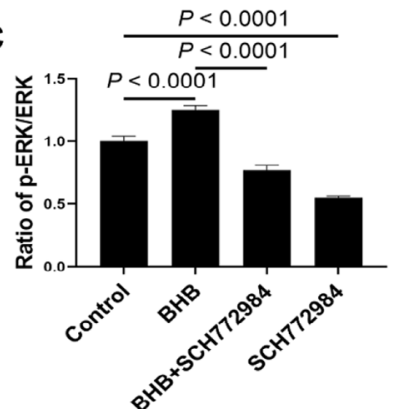

D

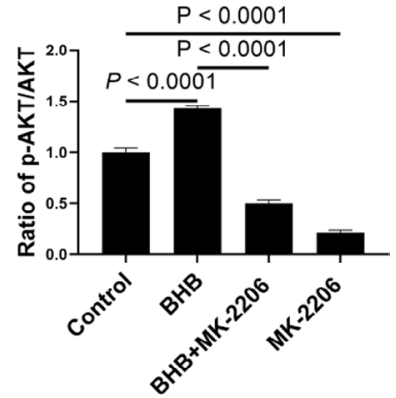

$\mathrm{F}$

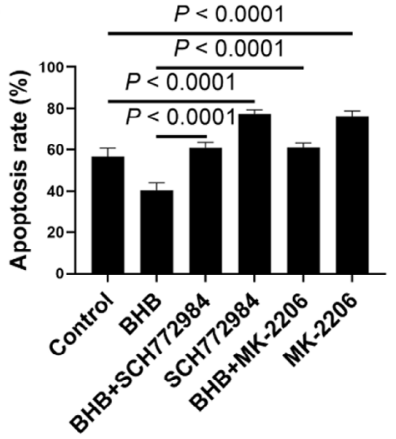

$\mathrm{H}$

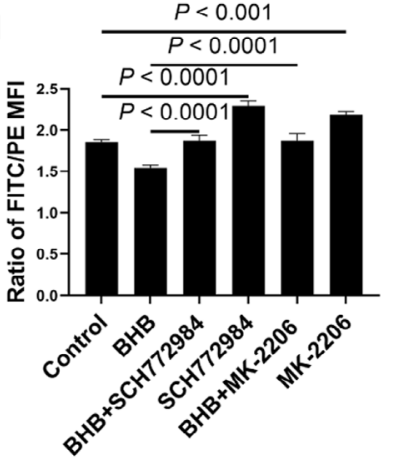

Figure 4. Effects of ERK1/2 and AKT signaling pathways on neutrophil apoptosis inhibited by BHB. SCH772984 (300 $\mu M, 8 \mathrm{~h})$ and MK$2206(200 \mu M, 8 \mathrm{~h})$ were used to inhibit the activation of ERK1/2 and AKT, respectively. (A) Protein phosphorylation level (p-) of ERK1/2. (B) Protein phosphorylation level of AKT. (C, D) Quantification of protein abundance in A and B, respectively; $\beta$-actin was used to normalize the protein levels. (E) Flow cytometry analysis of the effects of SCH772984 and MK-2206 on neutrophil apoptosis. Annexin V-fluorescein isothiocyanate and propidium iodide (FITC/PI) staining was used to identify apoptosis cells. The numbers in the top-right and bottom-right quadrants indicate the percentages of late and early apoptotic cells, respectively. Annexin $\mathrm{V}^{+}$cells were regarded as total apoptotic neutrophils. (F) Quantification of the total apoptotic rate of neutrophils in E. (G) Mitochondrial membrane potential (MMP) of neutrophils. Tetraethylbenzimidazolylcarbocyanine iodide (JC-1) monomers yielding green fluorescence were detected through the FITC channel of flow cytometry; JC-1 aggregates yielding red-colored fluorescence were detected through the phycoerythrin (PE) channel. The gating strategy is based on the distribution of cells in the negative staining control, the positive control, and the experimental groups. In the positive control, neutrophils were treated with carbonyl cyanide 3-chlorophenylhydrazone (CCCP) to reduce the MMP. Numbers in the bottom-right quadrants indicate the percentages of cells with low MMP. (H) Ratio of monomers to aggregates mean fluorescence intensity in control and treatment. Two-way ANOVA was performed to analyze differences by BHB and inhibitors, including a Bonferroni post hoc analysis. Two-way ANOVA showed a significant difference of BHB $\times$ SCH772984 interaction $(P<0.0001)$ and a significant difference of BHB $\times$ MK-2206 interaction $(P<$ 0.0001). Data expressed as mean \pm SEM. Statistical significance was declared at $P<0.05$, and $P<0.01$ was declared to be highly significant. 

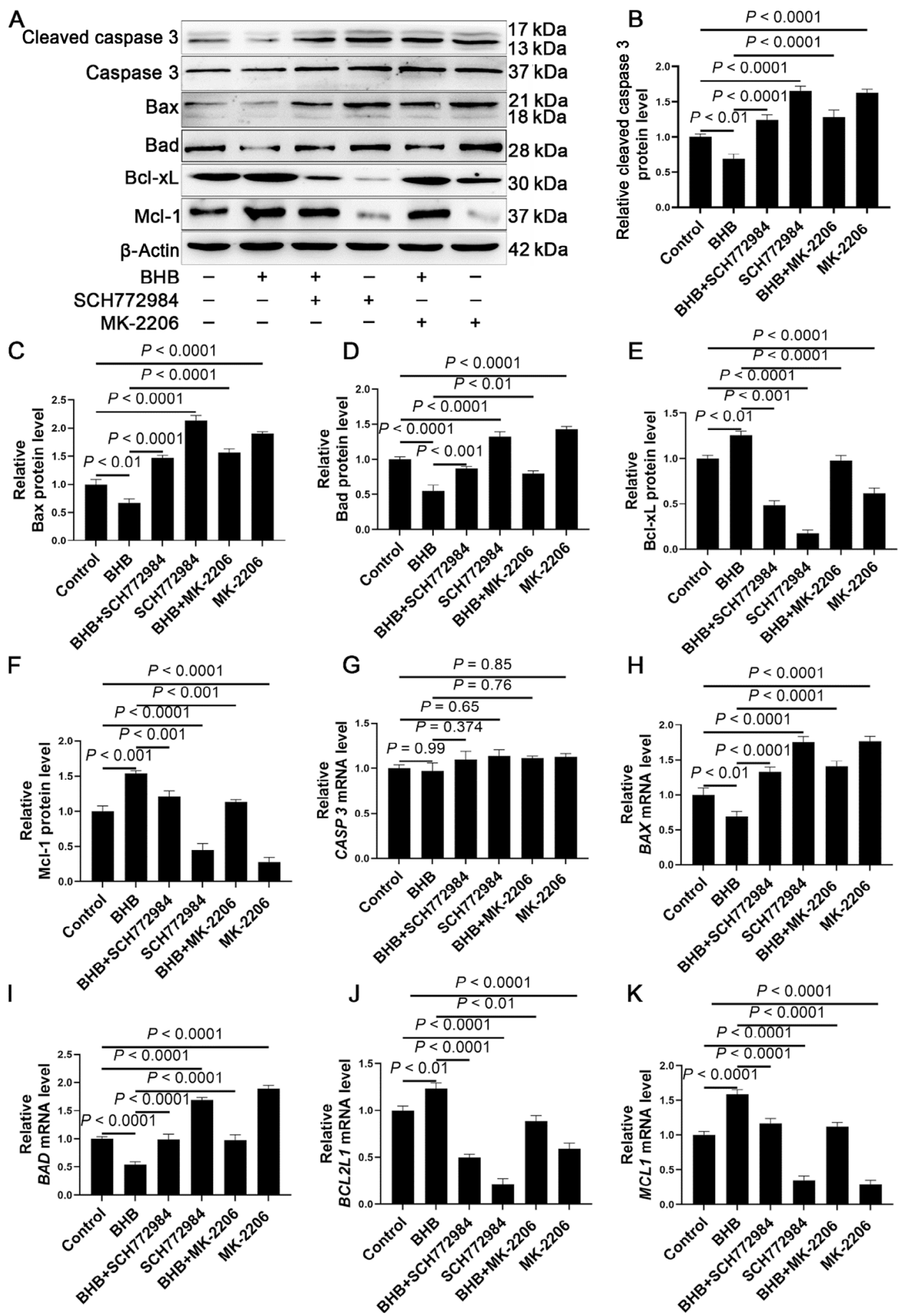

Figure 5. Effects of ERK1/2 and AKT signaling pathways on the expression of Bcl-2 family proteins. (A-F) Protein abundance of cleaved caspase 3, caspase 3, Bax, Bad, Bcl-xL, and Mcl-1. Representative blots in both groups are shown in A. Quantification is shown in B-F; (G-K) mRNA abundance of $C A S P 3, B A X, B A D, B C L 2 L 1$, and $M C L 1$. For WB experiments, $\beta$-actin was used to normalize protein abundance; for quantitative reverse-transcription PCR experiments, $A C T B$ and $Y W H A Z$ were used to normalize mRNA abundance. Two-way ANOVA was performed to analyze differences by BHB and inhibitors, including a Bonferroni post-hoc analysis when significant interaction occurred. Twoway ANOVA showed a significant difference of BHB $\times$ SCH772984 interaction $(P<0.0001)$ and a significant difference of BHB $\times$ MK-2206 interaction $(P<0.0001)$. Data expressed as mean \pm SEM. Statistical significance was declared at $P<0.05$, and $P<0.01$ was declared to be highly significant. 
cumulation of overactivated neutrophils in tissues, and promoting resolution of inflammation (Vago et al., 2012; Sugimoto et al., 2016). Emodin, a naturally occurring anthraquinone derivative in some Chinese herbs, can significantly reduce the recruitment of neutrophils and contribute to the resolution of inflammation in a murine model of rheumatoid arthritis, by promoting neutrophil apoptosis (Zhu et al., 2019). Thus, given the importance of ERK1/2 and AKT signaling in the control of neutrophil apoptosis, further studies in vivo with natural compounds such as emodin appear warranted.

Specific mechanisms whereby BHB activates ERK1/2 and AKT signaling pathways could not be discerned in the present study. However, potential targets can be considered in future studies. For instance, integrin subunit $\alpha \mathrm{M}$ (Itgam or Mac-1; a member of the $\beta 2$ integrin family) has been reported to activate both ERK1/2 and AKT signaling pathways and inhibit apoptosis of human and mouse neutrophils (Whitlock et al., 2000). Thus, the relationship between BHB and Mac-1 and the involvement of Mac-1 in the effect of BHB on apoptosis of bovine neutrophils could be a starting point for future studies.

In conclusion, the present study demonstrated that high concentrations of BHB inhibit apoptosis of bovine neutrophils through the ERK1/2- and AKT-mitochondrial pathways, providing new insights for the understanding of systemic inflammation of peripartal dairy cows with ketosis or severe NEB.

\section{ACKNOWLEDGMENTS}

This work was supported by the National Natural Science Foundation of China (Beijing; grant nos. 32022084 and 32102737). The authors have not stated any conflicts of interest.

\section{REFERENCES}

Abuajamieh, M., S. K. Kvidera, M. V. S. Fernandez, A. Nayeri, N. C. Upah, E. A. Nolan, S. M. Lei, J. M. DeFrain, H. B. Green, K. M. Schoenberg, W. E. Trout, and L. H. Baumgard. 2016. Inflammatory biomarkers are associated with ketosis in periparturient Holstein cows. Res. Vet. Sci. 109:81-85. https://doi.org/10.1016/ j.rvsc.2016.09.015.

Achanta, L. B., and C. D. Rae. 2017. $\beta$-Hydroxybutyrate in the brain: One molecule, multiple mechanisms. Neurochem. Res. 42:35-49. https://doi.org/10.1007/s11064-016-2099-2.

Adams, J. M., and S. Cory. 1998. The Bcl-2 protein family: Arbiters of cell survival. Science 281:1322-1326. https://doi.org/10.1126/ science.281.5381.1322.

Akgul, C., D. A. Moulding, and S. W. Edwards. 2001. Molecular control of neutrophil apoptosis. FEBS Lett. 487:318-322. https://doi .org/10.1016/S0014-5793(00)02324-3.

Antonsson, B., and J. C. Martinou. 2000. The Bcl-2 protein family. Exp. Cell Res. 256:50-57. https://doi.org/10.1006/excr.2000.4839.

Berge, A. C., and G. Vertenten. 2014. A field study to determine the prevalence, dairy herd management systems, and fresh cow clini- cal conditions associated with ketosis in western European dairy herds. J. Dairy Sci. 97:2145-2154. https://doi.org/10.3168/jds .2013-7163.

Boutet, P., D. Boulanger, L. Gillet, A. Vanderplasschen, R. Closset, F. Bureau, and P. Lekeux. 2004. Delayed neutrophil apoptosis in bovine subclinical mastitis. J. Dairy Sci. 87:4104-4114. https://doi .org/10.3168/jds.S0022-0302(04)73553-5.

Brostjan, C., and R. Oehler. 2020. The role of neutrophil death in chronic inflammation and cancer. Cell Death Discov. 6:26. https:/ /doi.org/10.1038/s41420-020-0255-6.

Carretta, M. D., Y. Barria, K. Borquez, B. Urra, A. Rivera, P. Alarcon, M. A. Hidalgo, and R. A. Burgos. 2020. $\beta$-Hydroxybutyrate and hydroxycarboxylic acid receptor 2 agonists activate the AKT, ERK and AMPK pathways, which are involved in bovine neutrophil chemotaxis. Sci. Rep. 10:12491. https://doi.org/10.1038/ s41598-020-69500-2.

Chen, G. H., Y. J. Yang, C. S. Xu, and S. Gao. 2018. A flow cytometry-based assay for measuring mitochondrial membrane potential in cardiac myocytes after hypoxia/reoxygenation. J. Vis. Exp. 2018:e57725. https://doi.org/10.3791/57725.

Crookenden, M. A., K. M. Moyes, B. Kuhn-Sherlock, K. Lehnert, C. G. Walker, J. J. Loor, M. D. Mitchell, A. Murray, V. S. R. Dukkipati, M. Vailati-Riboni, A. Heiser, and J. R. Roche. 2019. Transcriptomic analysis of circulating neutrophils in metabolically stressed peripartal grazing dairy cows. J. Dairy Sci. 102:7408-7420. https:/ /doi.org/10.3168/jds.2019-16367.

Daha, M. R. 2011. Grand challenges in molecular innate immunity. Front. Immunol. 2. https://doi.org/10.3389/fimmu.2011.00016.

Dalli, J., and C. N. Serhan. 2012. Specific lipid mediator signatures of human phagocytes: Microparticles stimulate macrophage efferocytosis and pro-resolving mediators. Blood 120:e60-e72. https://doi .org/10.1182/blood-2012-04-423525.

Davis, C., J. Fischer, K. Ley, and I. J. Sarembock. 2003. The role of inflammation in vascular injury and repair. J. Thromb. Haemost. 1:1699-1709. https://doi.org/10.1046/j.1538-7836.2003.00292.x.

De Ketelaere, A., K. Goossens, L. Peelman, and C. Burvenich. 2006. Technical note: Validation of internal control genes for gene expression analysis in bovine polymorphonuclear leukocytes. J. Dairy Sci. 89:4066-4069. https://doi.org/10.3168/jds.S0022 $-0302(06) 72450-\mathrm{X}$.

Du, X., T. Shen, H. Wang, X. Qin, D. Xing, Q. Ye, Z. Shi, Z. Fang, Y. Zhu, Y. Yang, Z. Peng, C. Zhao, B. Lv, X. Li, G. Liu, and X. Li. 2018a. Adaptations of hepatic lipid metabolism and mitochondria in dairy cows with mild fatty liver. J. Dairy Sci. 101:9544-9558. https://doi.org/10.3168/jds.2018-14546.

Du, X., Y. Zhu, Z. Peng, Y. Cui, Q. Zhang, Z. Shi, Y. Guan, X. Sha, T. Shen, Y. Yang, X. Li, Z. Wang, X. Li, and G. Liu. 2018b. High concentrations of fatty acids and $\beta$-hydroxybutyrate impair the growth hormone-mediated hepatic JAK2-STAT5 pathway in clinically ketotic cows. J. Dairy Sci. 101:3476-3487. https://doi.org/10 $.3168 /$ jds.2017-13234.

Duffield, T. F., K. D. Lissemore, B. W. McBride, and K. E. Leslie. 2009. Impact of hyperketonemia in early lactation dairy cows on health and production. J. Dairy Sci. 92:571-580. https://doi.org/ $10.3168 /$ jds.2008-1507.

Fass Inc. 2010. Guidelines for the Care and Use of Agricultural Animals in Research and Teaching. 3rd ed. Fass Inc. https://www.fass .org/images/science-policy/Ag_Guide_3rd_ed.pdf.

Guo, Q. H., S. M. Liu, S. D. Wang, M. Y. Wu, Z. X. Li, and Y. B. Wang. 2019. Beta-hydroxybutyric acid attenuates neuronal damage in epileptic mice. Acta Histochem. 121:455-459. https://doi .org/10.1016/j.acthis.2019.03.009.

Hammon, D. S., I. M. Evjen, T. R. Dhiman, J. P. Goff, and J. L. Walters. 2006. Neutrophil function and energy status in Holstein cows with uterine health disorders. Vet. Immunol. Immunopathol. 113:21-29. https://doi.org/10.1016/j.vetimm.2006.03.022.

Haslett, C. 1999. Granulocyte apoptosis and its role in the resolution and control of lung inflammation. Am. J. Respir. Crit. Care Med. 160(Suppl. 1):S5-S11. https://doi.org/10.1164/ajrccm.160 .supplement_1.4. 
Ibrahim, S. A., A. Kulshrestha, G. K. Katara, V. Riehl, M. Sahoo, and K. D. Beaman. 2020. Cancer-associated V-ATPase induces delayed apoptosis of protumorigenic neutrophils. Mol. Oncol. 14:590-610. https://doi.org/10.1002/1878-0261.12630.

Ingvartsen, K. L. 2006. Feeding- and management-related diseases in the transition cow. Anim. Feed Sci. Technol. 126:175-213. https:/ /doi.org/10.1016/j.anifeedsci.2005.08.003.

Ingvartsen, K. L., and K. Moyes. 2013. Nutrition, immune function and health of dairy cattle. Animal 7(Suppl. 1):112-122. https:// doi.org/10.1017/S175173111200170X.

Itle, A. J., J. M. Huzzey, D. M. Weary, and M. A. von Keyserlingk. 2015. Clinical ketosis and standing behavior in transition cows. J. Dairy Sci. 98:128-134. https://doi.org/10.3168/jds.2014-7932.

Kilpatrick, L. E., S. Sun, D. Mackie, F. Baik, H. Li, and H. M. Korchak. 2006. Regulation of TNF mediated antiapoptotic signaling in human neutrophils: Role of delta-PKC and ERK1/2. J. Leukoc. Biol. 80:1512-1521. https://doi.org/10.1189/jlb.0406284.

Koedel, U., T. Frankenberg, S. Kirschnek, B. Obermaier, H. Hacker, R. Paul, and G. Hacker. 2009. Apoptosis is essential for neutrophil functional shutdown and determines tissue damage in experimental pneumococcal meningitis. PLoS Pathog. 5:e1000461. https:// doi.org/10.1371/journal.ppat.1000461.

Korns, D., S. C. Frasch, R. Fernandez-Boyanapalli, P. M. Henson, and D. L. Bratton. 2011. Modulation of macrophage efferocytosis in inflammation. Front. Immunol. 2:57. https://doi.org/10.3389/ fimmu.2011.00057.

Lacetera, N., O. Franci, D. Scalia, U. Bernabucci, B. Ronchi, and A. Nardone. 2002. Effects on functions of ovine blood mononuclear cells for each of several fatty acids at concentrations found in plasma of healthy and ketotic ewes. Am. J. Vet. Res. 63:958-962. https://doi.org/10.2460/ajvr.2002.63.958.

Lawrence, S. M., R. Corriden, and V. Nizet. 2020. How neutrophils meet their end. Trends Immunol. 41:531-544. https://doi.org/10 $.1016 /$ j.it.2020.03.008.

Lindsay, J., M. D. Esposti, and A. P. Gilmore. 2011. Bcl-2 proteins and mitochondria - Specificity in membrane targeting for death. Biochim. Biophys. Acta 1813:532-539. https://doi.org/10.1016/j .bbamcr.2010.10.017.

Loor, J. J., R. E. Everts, M. Bionaz, H. M. Dann, D. E. Morin, R. Oliveira, S. L. Rodriguez-Zas, J. K. Drackley, and H. A. Lewin. 2007. Nutrition-induced ketosis alters metabolic and signaling gene networks in liver of periparturient dairy cows. Physiol. Genomics 32:105-116. https://doi.org/10.1152/physiolgenomics.00188.2007.

Medzhitov, R. 2010. Inflammation 2010: New adventures of an old flame. Cell 140:771-776. https://doi.org/10.1016/j.cell.2010.03 .006 .

Moyes, K. M., J. K. Drackley, J. L. Salak-Johnson, D. E. Morin, J. C. Hope, and J. J. Loor. 2009. Dietary-induced negative energy balance has minimal effects on innate immunity during a Streptococcus uberis mastitis challenge in dairy cows during midlactation. J. Dairy Sci. 92:4301-4316. https://doi.org/10.3168/jds.2009-2170.

Nakanishi, K., M. Sakamoto, S. Yamasaki, S. Todo, and S. Hirohashi. 2005. Akt phosphorylation is a risk factor for early disease recurrence and poor prognosis in hepatocellular carcinoma. Cancer 103:307-312. https://doi.org/10.1002/cncr.20774.

Ospina, P. A., D. V. Nydam, T. Stokol, and T. R. Overton. 2010. Evaluation of nonesterified fatty acids and $\beta$-hydroxybutyrate in transition dairy cattle in the northeastern United States: Critical thresholds for prediction of clinical diseases. J. Dairy Sci. 93:546554. https://doi.org/10.3168/jds.2009-2277.

Pathak, N., and S. Khandelwal. 2007. Role of oxidative stress and apoptosis in cadmium induced thymic atrophy and splenomegaly in mice. Toxicol. Lett. 169:95-108. https://doi.org/10.1016/j .toxlet.2006.12.009.

Pryce, J. E., K. L. Parker Gaddis, A. Koeck, C. Bastin, M. Abdelsayed, N. Gengler, F. Miglior, B. Heringstad, C. Egger-Danner, K. F. Stock, A. J. Bradley, and J. B. Cole. 2016. Invited review: Opportunities for genetic improvement of metabolic diseases. J. Dairy Sci. 99:6855-6873. https://doi.org/10.3168/jds.2016-10854.
Raju, I., K. Kannan, and E. C. Abraham. 2013. FoxO3a serves as a biomarker of oxidative stress in human lens epithelial cells under conditions of hyperglycemia. PLoS One 8:e67126. https://doi.org/ 10.1371/journal.pone.0067126.

Ravichandran, K. S. 2010. Find-me and eat-me signals in apoptotic cell clearance: Progress and conundrums. J. Exp. Med. 207:18071817. https://doi.org/10.1084/jem.20101157.

Rodriguez-Jimenez, S., K. J. Haerr, E. Trevisi, J. J. Loor, F. C. Cardoso, and J. S. Osorio. 2018. Prepartal standing behavior as a parameter for early detection of postpartal subclinical ketosis associated with inflammation and liver function biomarkers in peripartal dairy cows. J. Dairy Sci. 101:8224-8235. https://doi.org/10 $.3168 /$ jds.2017-14254.

Savill, J., and V. Fadok. 2000. Corpse clearance defines the meaning of cell death. Nature 407:784-788. https://doi.org/10.1038/ 35037722 .

Schulz, K., J. Frahm, S. Kersten, U. Meyer, D. Reiche, H. Sauerwein, and S. Danicke. 2015. Effects of elevated parameters of subclinical ketosis on the immune system of dairy cows: In vivo and in vitro results. Arch. Anim. Nutr. 69:113-127. https://doi.org/10.1080/ 1745039X.2015.1013666.

Shen, T. Y., F. Xu, Z. Y. Fang, J. J. Loor, H. S. Ouyang, M. Chen, B. Jin, X. H. Wang, Z. Shi, Y. W. Zhu, Y. S. Liang, L. X. Ju, Y. X. Song, Z. Wang, X. W. Li, X. L. Du, and G. W. Liu. 2021. Hepatic autophagy and mitophagy status in dairy cows with subclinical and clinical ketosis. J. Dairy Sci. 104:4847-4857. https://doi.org/ 10.3168/jds.2020-19150.

Shi, X., D. Li, Q. Deng, Y. Li, G. Sun, X. Yuan, Y. Song, Z. Wang, X. Li, X. Li, and G. Liu. 2015. NEFAs activate the oxidative stressmediated NF- $\mathrm{B}$ signaling pathway to induce inflammatory response in calf hepatocytes. J. Steroid Biochem. Mol. Biol. 145:103112. https://doi.org/10.1016/j.jsbmb.2014.10.014

Shi, X., X. Li, D. Li, Y. Li, Y. Song, Q. Deng, J. Wang, Y. Zhang, H. Ding, L. Yin, Y. Zhang, Z. Wang, X. Li, and G. Liu. 2014. $\beta$-Hydroxybutyrate activates the NF- $\kappa \mathrm{B}$ signaling pathway to promote the expression of pro-inflammatory factors in calf hepatocytes. Cell. Physiol. Biochem. 33:920-932. https://doi.org/10 $.1159 / 000358664$.

Shrivastava, S., M. K. Jeengar, V. S. Reddy, G. B. Reddy, and V. G. Naidu. 2015. Anticancer effect of celastrol on human triple negative breast cancer: Possible involvement of oxidative stress, mitochondrial dysfunction, apoptosis and PI3K/Akt pathways. Exp. Mol. Pathol. 98:313-327. https://doi.org/10.1016/j.yexmp.2015.03 .031 .

Sládek, Z., and D. Rysanek. 2001. Neutrophil apoptosis during the resolution of bovine mammary gland injury. Res. Vet. Sci. 70:41-46. https://doi.org/10.1053/rvsc.2000.0440.

Song, Y., N. Li, J. Gu, S. Fu, Z. Peng, C. Zhao, Y. Zhang, X. Li, Z. Wang, X. Li, and G. Liu. 2016. $\beta$-Hydroxybutyrate induces bovine hepatocyte apoptosis via an ROS-p38 signaling pathway. J. Dairy Sci. 99:9184-9198. https://doi.org/10.3168/jds.2016-11219.

Song, Y., J. J. Loor, C. Li, Y. Liang, N. Li, X. Shu, Y. Yang, X. Feng, X. Du, Z. Wang, G. Liu, and X. Li. 2021. Enhanced mitochondrial dysfunction and oxidative stress in the mammary gland of cows with clinical ketosis. J. Dairy Sci. 104:6909-6918. https://doi.org/ 10.3168/jds.2020-19964.

Sugimoto, M. A., J. P. Vago, M. M. Teixeira, and L. P. Sousa. 2016. Annexin A1 and the resolution of inflammation: Modulation of neutrophil recruitment, apoptosis, and clearance. J. Immunol. Res. 2016:1-13. https://doi.org/10.1155/2016/8239258.

Suthar, V. S., J. Canelas-Raposo, A. Deniz, and W. Heuwieser. 2013. Prevalence of subclinical ketosis and relationships with postpartum diseases in European dairy cows. J. Dairy Sci. 96:2925-2938. https://doi.org/10.3168/jds.2012-6035.

Tecchio, C., and M. A. Cassatella. 2014. Neutrophil-derived cytokines involved in physiological and pathological angiogenesis. Chem. Immunol. Allergy 99:123-137. https://doi.org/10.1159/000353358.

Vago, J. P., C. R. C. Nogueira, L. P. Tavares, F. M. Soriani, F. Lopes, R. C. Russo, V. Pinho, M. M. Teixeira, and L. P. Sousa. 2012. An- 
nexin A1 modulates natural and glucocorticoid-induced resolution of inflammation by enhancing neutrophil apoptosis. J. Leukoc. Biol. 92:249-258. https://doi.org/10.1189/jlb.0112008.

Whitlock, B. B., S. Gardai, V. Fadok, D. Bratton, and P. M. Henson. 2000. Differential roles for $\alpha_{M} \beta_{2}$ integrin clustering or activation in the control of apoptosis via regulation of Akt and ERK survival mechanisms. J. Cell Biol. 151:1305-1320. https://doi.org/10.1083/ jcb.151.6.1305.

Xie, G., W. Tian, T. Wei, and F. Liu. 2015. The neuroprotective effects of $\beta$-hydroxybutyrate on $\mathrm{A} \beta$-injected rat hippocampus in vivo and in $\mathrm{A} \beta$-treated PC-12 cells in vitro. Free Radic. Res. 49:139150. https://doi.org/10.3109/10715762.2014.987274.

Zhang, X. Z., L. Ding, and A. J. Sandford. 2005. Selection of reference genes for gene expression studies in human neutrophils by real-time PCR. BMC Mol. Biol. 6:4. https://doi.org/10.1186/1471 -2199-6-4.

Zhu, D., H. Hattori, H. Jo, Y. Jia, K. K. Subramanian, F. Loison, J. You, Y. Le, M. Honczarenko, L. Silberstein, and H. R. Luo. 2006. Deactivation of phosphatidylinositol 3,4,5-trisphosphate/ Akt signaling mediates neutrophil spontaneous death. Proc. Natl. Acad. Sci. USA 103:14836-14841. https://doi.org/10.1073/pnas .0605722103 .

Zhu, M. M., K. Yuan, Q. Y. Lu, Q. Q. Zhu, S. Zhang, X. H. Li, L. Zhao, H. S. Wang, G. B. Luo, T. Wang, G. R. Huang, and A. L. Xu. 2019. Emodin ameliorates rheumatoid arthritis by promoting neutrophil apoptosis and inhibiting neutrophil extracellular trap formation. Mol. Immunol. 112:188-197. https://doi.org/10.1016/ j.molimm.2019.05.010. 